\title{
Implementasi Integrated Learning Berbasis Saintifik-Religius Bagi Guru Madrasah di Kota Malang
}

\author{
Nurul Ulfatin ${ }^{1}$, Maisyaroh ${ }^{2}$, Djum-Djum Noor Benty ${ }^{3}$, Bagus Rachmad Saputra ${ }^{4}$, Amat \\ Mukhadis ${ }^{5}$ \\ 1,2,3,4 Jurusan Administrasi Pendidikan, Fakultas Ilmu Pendidikan, Universitas Negeri Malang \\ ${ }^{5}$ Fakultas Teknik-Universitas Negeri Malang \\ 11 nurul.ulfatin.fip@um.ac.id \\ ${ }^{2}$ maisyaroh.fip@um.ac.id \\ 3djum.djum.fip@um.ac.id \\ 함ogusrachmad47@gmail.com \\ 5 amat.mukhadis.ft@um.ac.id
}

\begin{abstract}
ABSTRAK
Sekolah berjenis madrasah di dalamnya terdapat dua macam kurikulum umum dan agama sementara jumlah jam pelajaran terbatas. Perlu pemahaman guru di madrasah dalam memahami bagaimana memadukan muatan kurikulum dengan kurikulum berbasis agama dalam aktivitas pembelajaran. Kegiatan pengabdian ini bertujuan membantu guru di madrasah agar dapat memilih strategi pembelajaran yang lebih efektif dan efisien. Kegiatan ini bertujuan untuk melatih guru madrasah agar memiliki keterampilan tentang integrated learning dan mengimplementasikannya dengan mengintegrasikan sejumlah matapelajaran yang berbasis saintifik dan religious. Metode pengabdian adalah workshop yang diikuti oleh kepala sekolah dan guru. Pelatihan melibatkan 30 orang guru di dua madrasah tsanawiyah di Kota Malang, Jawa Timur. Kegiatan dilakukan melalui empat tahap yaitu refleksi dan persiapan, sosialisasi materi, workshop, dan peer teaching. Hasil kegiatan pengabdian adalah pemahaman guru tentang integrated learning masih rendah. Beberapa matapelajaran dapat diintegrasikan dengan model pembelajaran connected dan threaded. Dua di antaranya (Akidah Akhlak yang bermuatan religious dan IPA yang bermuatan saintifik) dipilih sebagai contoh penerapan integrated learning oleh peserta dalam peer teaching.
\end{abstract}

Kata kunci: integrated learning, saintifik, religious, connected, threaded, madrasah tsanawiyah

\section{ABSTRACT}

Madrasah type schools in which there are two kinds of general curriculum and religion while the number of hours of study is limited. It is necessary to understand teachers in madrasas in understanding how to integrate curriculum content with afama-based curriculum in learning activities. This service activity aims to help teachers in madrasas to be able to choose learning strategies that are more effective and efficient. This activity aims to train madrasa teachers to have integrated learning skills and implement them by integrating a number of scientific and religious based subjects. The dedication method is a workshop attended by the principal and teachers. The training involved 30 teachers in two tsanawiyah madrasas in Malang, East Java. The activity was carried out through four stages, namely reflection and preparation, material socialization, workshops, and peer teaching. The result of community service activities is that teachers' understanding of integrated learning is still low. Several subjects can be integrated with connected and threaded learning models. Two of them (religious creed and science-based science) were selected as examples of the application of integrated learning by participants in peer teaching.

Keywords: integrated learning, scientific, religious, connected, threaded, madrasah tsanawiyah

\section{PENDAHULUAN}

Permasalahan yang dihadapi oleh sekolah berbasis madrasah sejak tahun 2006 dengan diterapkannya Kurikulum Tingkat Satuan Pendidikan (KTSP), para guru pendidikan dasar diarahkan untuk menerapkan praktik pembelajarannya dengan pendekatan tematik. Pendekatan tematik untuk pendidikan dasar diperkuat pada Kurikulum 2013 dengan menekankan muatan pendekatan 
saintifik. Pembelajaran tematik adalah kegiatan pembelajaran yang menggunakan tema untuk mengaitkan beberapa matapelajaran atau bidang studi untuk memberikan pengalaman yang lebih bermakna kepada peserta didik. Karena itulah pembelajaran tematik disebut juga pembelajaran terintegrasi atau integrated learning (Akbar, 2018; Fogarty, 1993; Ulfatin, $\mathrm{N}$ dan Mukhadis, 2018) Pembelajaran yang mengacu pada tema atau terintegrasi sebenarnya bukanlah sesuatu yang baru bagi para guru/pendidik karena dalam praktik kehidupan sehari-hari, setiap kegiatan seseorang (termasuk peserta didik) selalu mengaitkan beberapa bidang pengalaman dan pelajaran. Namun karena sudah berpuluhpuluh tahun kurikulum di sekolah lebih banyak menggunakan struktur kurikulum matapelajaran yang terpisah-pisah (subject matterl separated curriculum), maka pembelajaran tematik kurang mendapat perhatian.

Selama ini guru lebih banyak mengajar secara terpisah-pisah sesuai matapelajarannya masing-masing. Misalnya guru matematika hanya mengajarkan pengetahuan, pengalaman, dan kemampuan terkait pengathuan atau ilmu matematika saja(Adnan, Amran, A, Asmah, 2020; Ulia \& Hariyono, 2020). Guru Bahasa hanya mengajarkan/membelajarkan pengetahuan, pengalaman, dan kemampuan yang terkait dengan pengetahuan atau ilmu bahasa saja. Begitu juga guru agama hanya mengajarkan/ membelajarkan pengetahuan, pengalaman dan kemampuan tentang agama tanpa mengaitkan dengan pengetahuan atau ilmu-ilmu yang lainnya (Ulfatin, $\mathrm{N}$ dan Mukhadis, 2018). Sebagai akibatnya, hasil belajar (terutama yang diterapkan dalan kehidupan sehari-hari) bagi peserta didik bisa dikatakan terpisah-pisah. Kita bisa menemukan dan sangat mungkin terjadi seorang peserta didik hanya mengejar kemampuan atau nilai hasil belajar matematika karena matematika merupakan matapelajaran inti yang hasilnya diujikan secara nasional. Sebaliknya, matapelajaran agama kurang mendapat perhatian dengan jumlah jam pelajaran yang sangat sedikit karena pelajaran agama tidak diujikan secara nasional. Akibatnya matapelajaran agama hanya bersifat pengetahuan. Fenomena seperti ini ternyata tidak hanya terjadi di sekolah umum, tetapi juga terjadi di sekolah-sekolah berbasis agama (Islam) konvensional pada jenjang pendidikan dasar seperti madrasah ibtidaiyah dan madrasah stanawiyah.

Madrasah-madrasah yang konvensional untuk jenjang pendidikan dasar dengan jumlah jam belajar yang sangat terbatas (sama dengan sekolah umum), sementara diberlakukan dua kurikulum (agama dan umum), dan untuk mencapai persaingan hasil belajar dengan sekolah umum melalui hasil ujian nasional, maka kebijakan sekolah menetapkan jam pelajaran lebih banyak digunakan untuk pembelajaran matapelajaran umum. Karena itulah guru seharusnya memiliki keterampilan untuk memilih model pembelajaran yang tepat untuk mencapai dua kurikulum dalam waktu yang bersamaan. Satu bentuk pembelajaran itu bersifat tematik yang dapat diterapkan dengan mengintegrasikan beberapa matapelajaran dalam satu rancangan pembelajaran. Jenis pembelajaran tematik ini sangat tepat dan sangat disarankan adalah berbasis saintifik-religius karena tujuan pendidikan berbasis agama adalah memberikan bekal keagamaan sebagai dasar dalam menjalankan agama sehari-hari. Begitu juga dalam waktu yang sama harus diberikan bekal dasar-dasar perpikir, bersikap dan berpengetahuan yang menyeluruh secara saintifik untuk matapelajaran umum sesuai perkembangan usia kronologis dimana anak usia pendidikan dasar berada pada tingkat perkembangan berpikir operasional konkrit dan menyeluruh.

\section{Integrated Learning di Madrasah}

Di sekolah-sekolah yang berbasis agama (termasuk di dalamnya sekolah-sekolah berjenis madrasah), integrated learning atau pembelajaran tematik sangat dibutuhkan. Hal ini karena dengan integrated learning maka pembelajaran bidang agama dan bidang umum bisa disatukan sehingga dapat membentuk perilaku yang utuh atau mencerminkan perilaku yang secara keseluruhan memenuhi kompetensi agama dan umum. Dalam pandangan Islam, orang yang memiliki kompetensi agama dan umum semacam ini berpotensi mampu menjalankan Islam secara menyeluruh atau komprehensif atau dapat diistilahkan dengan "kaffah". Penurut pemahaman penulis, menjalankan agama (Islam) tidak hanya sebatas ritual dalam rukun Islam saja atau terkait dengan sebagian ajaran saja, tetapi menyatu dalam seluruh kehidupan dan menyatu dalam keseluruhan dan kedalaman rukun Islam itu sendiri. Misalnya ibadah puasa, jika dijalankan secara kaffah 
maka di dalamnya tidak hanya sekedar membutuhkan ilmu yang tekait dengan doktrin bahwa tidak makan dan minum dari waktu subuh sampai maghrib, tetapi di dalamnya membutuhkan ilmu yang terkait dengan kesehatan, biologi, social, dan ilmu atau bidang-bidang lainnya. Dengan demikian, ketika kita menjalankan ibadah puasa, berarti di dalamnya ada dimensi aspek ketaatan, kesehatan, social, dan sebagainya. Begitu juga sebaliknya, jika kita menjalankan kehidupan (duniawi), misalnya yang terkait dengan pekerjaan di bidang kesehatan atau biologi, maka jika tidak disertai bidang agama (Islam) di dalamnya, bisa jadi apa yang kita kerjakan semata-mata hanya mengejar kebutuhan duniawi (yang mungkin bisa jadi terpisah atau tidak bernilai agama), bahkan sangat mungkin bisa menjadikan kekufuran (naudzubillah).

Bertolak dari rasional di atas, maka upaya guru sebagai pendidik (terutama di lembaga-lembaga pendidikan Islam) pada tingkat pendidikan dasar dapat dilakukan dengan membekali para peserta didik untuk mampu menselaraskan bahkan mengintegrasikan banyak bidang ilmu pengetahuan agar perilaku kaffah itu sudah tertanam dan menyatu ke dalam kehidupan sehari-hari sejak dini.

\section{METODE KEGIATAN}

Artikel ini ditulis dari hasil kegiatan pengabdian kepada masyarakat dengan metode pelatihan, workshop, dan simulasi peer teaching tentang integrated learning berbasis saintifik-religious di madrasah. Kegiatan dilakukan secara intensif selama tiga bulan (Agustus-Oktober 2019) dengan empat kali tatap muka secara klasikal, dan konsultasi/pendampingan secara online yang melibatkan 30 orang guru bidang studi dari dua madrasah tsanawiyah (MTs) swasta di kota Malang, Jawa Timur. Empat kali tatap muka secara klasikal digunakan untuk (1) pengenalam materi melalui presentasi makalah dari tim pelaksana dan pemutaran/pembahasan isi video integrated learning (produk hasil penelitian yang telah dilakukan oleh pengabdi), (2) workshop pelatihan dan penyusunan rencana pelaksanaan pembelajaran (RPP), dan (3) simulasi peer teaching untuk menerapkan hasil rancangan pembelajaran yang telah dibuat melalui workshop.

\section{HASIL \& PEMBAHASAN}

Sebagaimana penerapan integrated learning pada beberapa matapelajaran yang telah dicontohkan pengabdi melalui tayangan video yang dihasilkan dari penelitian oleh personil tim pelaksana (Ulfatin, $\mathrm{N}$ dan Mukhadis, 2018), melalui kegiatan pengabdian kepada masyarakat ini para guru di madrasah (MTs) dapat menerapkannya metode pembelajaran secara lebih bervariasi. Satu bentuk variasi yang dipilih adalah mengintegrasikan matapelajaran umum dan agama. Matapelajaran kelompok umum (mengacu pada kurikulum dari Kementerian Pendidikan dan Kebudayaa atau Kurikulum 2013) diasumsikan sebagai matapelajaran yang sarat bermuatan isi materi saintifik. Materi saintifik ditandai oleh kegiatan pembelajaran matapelajaran umum dengan serangkaian aktivitas mengamati, menanya, mencipta, mencoba, dan mengkomunikasikan, Sedangkan matapelajaran kelompok agama (mengacu pada kurikulum dari Kementerian Agama) diasumsikan sebagai matapelajaran yang sarat bermuatan isi agama dengan aktivitas yang sifatnya pembentukan karakter. Pembelajaran terintegrasi dari kedua kelompok matapelajaran itu disebut integrated learning berbasis saintifik-religius.

$$
\text { Upaya mengintegrasikan }
$$

matapelajaran umum (diasumsikan identic dengan sarat muatan saintifik) dan agama (diasumsikan identic sarat dengan muatan religious) ini dinilai sangat realistis dan penting untuk diterapkan terutama untuk menanamkan cara berpikir, mampu memecahkan masalah secara akademis (teoritis) dan sekaligus mampu bertindak dan bersikap sesuai dengan ajaran agama. Istilah saintifik dipahami oleh guru berangkat dari cara berpikir tentang ilmu pengetahuan alam (IPA) yang dirumuskan berhubungan dengan gejala-gejala kebendaan dan didasarkan terutama atas pengamatan dan deduksi. Pendidikan IPA menekankan pada pemberian pengalaman langsung untuk mencari tahu dan berbuat sehingga mampu menjelajahi dan memahami alam sekitar secara ilmiah. Cara berpikir IPA identik sebagai cara untuk mencari tahu yang berdasarkan pada pengamatan, perekaman, penganalisisan, pembuktian, dan penemuan. Seorang guru dituntut memiliki kemampuan dan kreativitas yang cukup agar bisa melakukan pembelajaran secara inkuiri ilmiah (scientivic inquiry) untuk menumbuhkan kemampuan berpikir, bekerja, dan bersikap ilmiah serta berkomunikasi 
sebagai aspek penting dalam kehidupan(Anderson et al., 2004; Birenbaum et al., 2006; Kim, 2015). Dengan demikian dapat disimpulkan bahwa pembelajran yang saintifik dipahami oleh guru madarasah sebagai pembelajaran yang lebih menekankan pada proses ilmiah, yang banyak mengandalkan rasio untuk bisa melakukan pembuktian melalui pengamatan yang empiris.

Sebaliknya, pada pendidikan agama (yang diasumsikan sarat bermuatan religious) selama ini hanya dibelajarkan dalam bentuk tatacara ritual ibadah (seperti cara sholat, berpuasa, dan sebagainya). Dalam pelajaran kelompok agama (Qur'an-Hadis, Figih, Ahlak, dan lainnya) tujuannya lebih banyak untuk membekali peserta didik agar memiliki pengetahuan, kemampuan dan sikap agamis. Menurut pengakuan guru-guru bidang studi agama, selama ini metode yang mereka gunakan lebih banyak ceramah dengan materi yang diambil dari buku agama, penyampaian kisah dan contoh-contoh teladan, dan praktek ritual ibadah. Pengakuan peserta, mereka belum pernah secara sengaja dan terstruktur mengaitkan materi pelajaran agama dengan materi dalam pelajaran lain (pelajaran umum) dalam satu rancangan kegiatan pembelajaran.

Berangkat dari pengalaman kedua kelompok guru matapelajaran (umum dan agama) sebagai peserrta, maka mereka dilatih mengintegrasikan pembelajarannya yang antara lain dapat dicontohkan sebagai berikut. Pada pembelajaran kelas VIII semester pertama, diintegrasikan dua matapelajaran yaitu Akidah Akhlak (untuk mengintegrasikan religius) dan IPA (untuk mengintegrasikan saintifik). Pada rancangan pembelajaran (RPP) yang disiapkan oleh guru, kompetensi inti yang akan dicapai adalah (1) menghargai dan menghayati ajaran agama yang dianutnya; (2) menghargai dan menghayati perilaku jujur, disiplin, tanggung jawab, peduli, toleransi, santun, percaya diri dalam berinteraksi secara efektif dengan lingkungan social dan alam dalam jangkauan, pergaulan dan keberadaannya; dan (3) memahami pengetahuan faktual, konseptual dan procedural berdasarkan rasa ingin tahu tentang ilmu pengetajhuan, teknologi, seni, budaya terkait fenomena dan kejadian yang tampak mata.

Pada matapelajaran Akidah Akhlak kompetensi yang ingin dicapai adalah memahami pengertian, contoh dan dampak positif sifat tawakal, ikhtiar, sabar, syukur dan qona'ah, yang ditandai oleh indicator antara lain (1) memahami akhlak terpuji pada diri sendiri (sifat-sifat tawakal, ikhtiar, sabar, syukur dan qona'ah), dan (2) berperilaku sebagai seseorang yang memiliki akhlak terpuji pada diri sendiri (sifat-sifat tawakal, ikhtiar, sabar, syukur dan qona'ah) dalam kehidupan. Sedangkan pada matapelajaran IPA, kompetensi yang ingin dicapai adalah menerapkan konsep pewarisan sifat dalam pemuliaan dan kelangsungan mahkluk hidup, dengan indicator (1) memahami pewarisan sifat yang ada pada manusia, dan (2) mengenali karakteristik anggota keluarga untuk menemukan hukum pewarisan sifat.

Dalam praktik pembelajaran melalui metode problem based learning, integrasi religious dan saintifik tampak sejak mulai membuka pelajaran. Jika umumnya ucapan salam dilakukan oleh guru untuk mengawali pelajaran, tetapi pada simulasi yang dipraktikkan di sini, salam pembuka diucapkan oleh siswa secara bersama-sama. Untuk menarik perhatian dan memupuk motivasi sebelum pembelajaran, guru melakukan aktivitas ice breaking dalam bentuk gerakan tangan-tubuh diikuti dengan ucapan teriakan "semangat". Untuk memulai kegiatan, guru melakukan appersepsi dengan mengajukan satu pertanyaan terkait dengan materi sebelumnya. Kegiatan berikutnya dilakukan eksplorasi dan penguatan dengan cara siswa memperhatikan beberapa gambar yang ada dalam suatu cerita dengan tema "keluarga seorang sahabat Nabi" yang ditunjukkan oleh guru seperti contoh Gambar 1. Pada cerita yang bergambar itu pesan singkat yang ingin disampaikan adalah (1) beberapa contoh perilaku tergong akhlak terpuji, dan (2) satu keluarga memiliki pewarisan genetika yang terus terjadi pada keturunannya, dan (3) namun penurunan genetika tidak selalu otomatis diikuti dengan penurunan keahlian profesi atau pekerjaan. Setelah mengamati gambar, siswa secara berpasangan mengidentifikasi sifat, tindakan, peran yang dimainkan oleh tokoh cerita yang kemudian dievaluasi oleh teman pasangannya. Begitu seterusnya secara bervariasi antara kegiatan mengamati, mencatat, menilai dan menunjukkan contoh tindakan dilakukan secara berpasangan yang di dalamnya terkandung pesan sifat tawakal, ikhtiar, sabar, syukur dan qona'ah dalam matapelajaran Akidah Akhlak dan pesan pemahaman pewarisan sifat yang ada pada manusia dalam keluarga pada matapelajaran IPA. Bukti-bukti aktivitas pembelajaran yang menunjukkan proses bermuatan saintifik dan 
religius dapat dilihat pada Gambar 2a dan $2 b$.

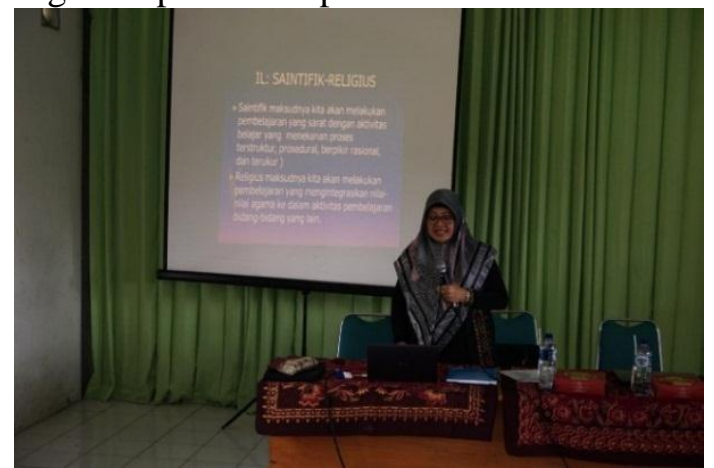

Gambar 1 Fasilitator sedang menjelaskan konsep integrated learning berbasis saintifik-religius

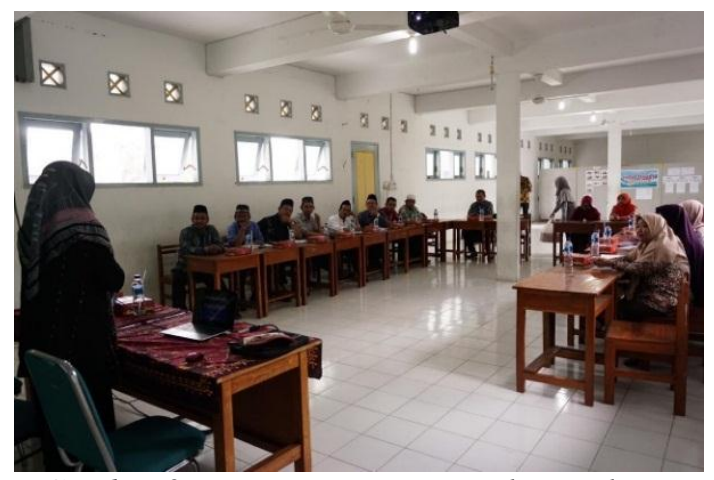

Gambar 2 Para peserta menyimak penjelasan fasilitator tentang konsep integrated learning berbasis saintifik-religius

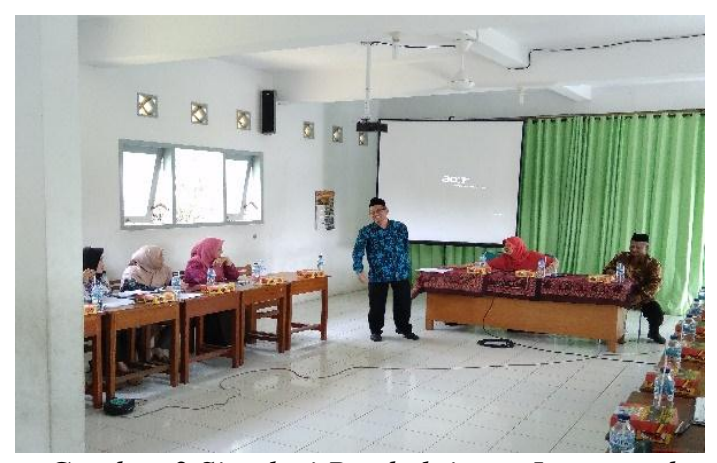

Gambar 3 Simulasi Pembelajaran Integrated Leraning Berbasis Saintifik Religius

Evaluasi pembelajaran dalam integrated learning yang berbasis saintifikreligius ini lebih menekankan aspek proses dan bukan hasil. Evaluasi hasil tidak bisa dilakukan dalam jangka pendek karena kompetensi yang ingin dicapai berupa sifat-sifat yang terintegrasi dalam kehidupan seharihari(Drianah, 2017; Riyanta, 2016). Untuk mengukur sifat-sifat dalam kehidupan seharihari memerlukan authentic assessment yang tidak cukup jika dilakukan dalam proses kegiatan di kelas dengan jumlah jamyang sangat singkat. Oleh karena itu, dalam jangka pendek di kelas, evaluasinya ditekankan pada kebenaran prosesnya yang diukur melalui pengamatan yang dibantu oleh lembar dan rubric pengamatan proses. Aspek-aspek yang diukur dalam pengamatan antara lain (1) ketepatan konsep, (2) urutan procedural tindakan, (3) kecepatan dalam mengenali sifat dan perilaku.

Berdasarkan hasil kegiatan sebagaimana diuraikan di atas dapat disimpulkan bahwa integrated learning dapat diterapkan secara bervariasi. Satu bentuk variasi yang dilatih dan dicobakan oleh guru di MTs adalah integrasi muatan matapelajaran umum dan agama. Cara pengintegrasiannya dilakukan dengan (1) pemilihan matapelajaran yang cocok untuk diintegrasikan (dalam hal ini matapelajaran Akidah Akhlak dan IPA), (2) pemilihan metode pembelajaran yang memungkinkan mengandung banyak aktivitas belajar (dalam hal ini dipilih broblem based learning), dan (3) pemilihan aktivitas pembelajaran yang mana satu jenis aktivitas bermuatan beberapa unsur nilai yang diintegrasikan yang menekankan kebenaran aspek proses (saintifik) dan aspek sifat mulia (religius).

Jika dilakukan analisis, cara integrasi yang dipilih oleh guru MTs tersebut menurut (Fogarty, 1993) disebut the integrated model yang berentang dari connected model sampai immersed model. Menurut (Fogarty, 1993) ada sepuluh model pembelajaran yang dapat dipilih guru secara berentang, yaitu (1) model terpenggal (the fragmented model), (2) model terambung (the connected model), (3) model tersarang (the nested model), (4) model terurut (the sequenced model), (5) model terbagi (the shared model), (6) model terjaring_laba-laba (the webbed model), (7) model terikat_benang (the threaded model), (8) model terpadu (the integrated model), (9) model terbenam (the immersed model), dan (10) model terjaring (the networked model). Model-model tersebut menggambarkan banyaknya variasi integrasi untuk menjadikan pembelajaran lebih menarik sesuai kebutuhan siswa dan sesuai matei atau topik matapelajaran. Hasil integrasi yang dilakukan oleh guru-guru di MTs yang dekat dengan connected dan threaded model dapat dilihat dari content matapelajaran yang saling terkait. Esensi dari connected model adalah menggali potensi yang bisa dihubung-hubungkan. Upaya ini dilakukan dlam rangka membantu siswa di dalam aktivitasnya memahami keterkaitan materi yang satu dengan materi yang lain. Hal ini dilakukan karena siswa dianggap tidak bisa menghubungkan antar materi secara otomatis. 
Sementara, threaded model dimana guru memiliki keyakinan bahwa di balik setiap matapelajaran mengandung "metacurricular" yang di dalamnya tersirat banyak keterampilan (thinking skills, social skills, multiple intelligences) melalui bermacam-macam bidang ilmu. Dalam threaded model, keterampilan-keterampilan tersebut diyakini tersirat pada metacurricular yang diibaratkan seperti serabut yang harus dikaitkan secara hati-hati menjadi rangkaian persoalan pada broblem based learning.

Model integrasi yang dipraktekkan oleh guru-guru MTs ini menurut (Trianto, 2007) disebut integrasi antar disiplin ilmu karena mengintegrasikan ilmu umum dan agama. Trianto mengemukakan tiga alternatif pembelajaran, yaitu (1) mengintegrasikan beberapa matapelajaran dalam satu bidang ilmu yang serumpun (inter-disipliner), misalnya metabolisme untuk membelajarkan tema dalam biologi dan kimia; mengintegrasikan beberapa matapelajaran dengan rumpun ilmu yang berbeda menjadi satu tema (antar disiplin ilmu), misalnya energi untuk membelajarkan tema dalam IPA dan IPS; dan (3) mengintegrasikan banyak matapelajaran tanpa dibatasi rumpun ilmuanya, misalnya tema rokok dapat untuk membelajarkan banyak bidang ilmu, antara lain kimia, biologi, fisika, ekonomi, budaya, bahkan agama.

Integrated learning yang diterapkan oleh guru-guru MTs tidak sama dengan integrated yang dilakukan oleh guru-guru di sekololah dasar (SD) atau di Madrasah Ibtidaiyah (MI). Meskipun MTs dan MI atau $\mathrm{SD}$, keduanya termasuk pendidikan dasar, namun cara pembelajarannya sudah berbeda(Akbar, 2018). Pada SD, integrasi dilakukan mulai dari tema yang di dalamnya mengintegrasikan bermacam-macam bidang materi dan keahlian(Miaz \& Putra, 2020). Mencampurkan matapelajaran dalam tema diibaratkan seperti mencampur (mix) bermacam-macam buah (mangga, melon, apel, dan sebagainya) untuk dibuat oleh mixer menjadi jus buah campur. Dengan demikian jus buah campur itu tidak tampak lagi bentuk dan rasa masing-masing buah yaitu yang mana mangga, melon, atau apel). Dengan integrated curriculum berarti lebih menampakkan tema yang dipelajari dan bukan nama matapelajarannya. Menurut (Akbar, S., Enrika, K., Hafi, D. Dwiharini, 2015; Akbar, 2018; Trianto, 2007), tema inilah yang menjadi pusat perhatian dalam suatu pembelajaran dan biasanya tema ini mencerminkan suatu masalah atau topik tertentu. Misalnya, suatu masalah yang ada di beberapa matapelajaran yang diintegrasikan dirancang dengan mengacu pada satu topik tertentu. Penyatuan masalah dalam bentuk topik ini biasa disebut dengan pembelajaran unit (unit teaching) (Hendriana \& Afrilianto, 2017; Ulfatin, N dan Mukhadis, 2018)

\section{Integrated learning berbasis saintifik dan religius}

Integrated learning yang menonjolkan aspek religious sudah hal biasa di madrasah (MTs) karena kurikulum agama dipilah menjadi beberapa matapelajaran. Begitu juga mengintegrasikan antar matapelajaran agama adalah hal yang biasa terjadi dalam kegiatan pembelajaran seharihari. Namun, integrasi matapelajaran agama (sebagai representasi religious) dan matapelajaran umum (sebagai representasi aktivitas saintifik) di madrasah dianggap sesuatu yang baru bagi guru. Hal ini sangat disadari oleh para peserta pelatihan sebagaimana terjadi di MTs Nurul Huda dan Sunan Kalijogo kota Malang ini. Hal ini semakin dirasakan dan menjadi sangat penting untuk dilatihkan karena hasil belajar peserta didik di MTs (keduanya berstatus swasta) tergolong rendah dan hal itu disinyalir karena konsep berpikir para guru di masa lampau menurut (Kovalik, S., \& Olsen, 1994) dianggap salah. Menurut Kovalik, di masa lalu ada kesalahan konsep berpikir dalam memandang pendidikan yang disebut Mismemes in education. Kovalik mengidentifikasi ada enam kesalahan yang perlu dicermati, yaitu (1) all students learn in the same way, (2) yesterday's curriculum is good enough for today, (3) words create knowledge, (4) acquisition of knowledge and skills is the goal of education, (5) textbooks equal curriculum and instruction, dan (6) changing one aspect of the system is sufficient. Bertolak dari pemahaman Kovalik ini menunjukkan betapa pentingnya bagi guru yang mengajar di madrasah yang tidak bisa disamakan caranya dengan para guru di sekolah umum.

Sebagimana yang dicontohkan pada pembelajaran di MTs tempat pelatihan ini, integrasi terjadi pada matapelajaran agama dan pelajaran IPA. Dengan kompetensi inti yang seolah-olah tidak bisa sambung (dicontohkan memahami akhlak terpuji pada diri sendiri (sifat-sifat tawakal, ikhtiar, sabar, syukur dan qona'ah) sebagai representasi basis religious, 
dan kompetensi inti menerapkan konsep pewarisan sifat dalam pemuliaan dan kelangsungan mahkluk hidup (dicontohkan memahami pewarisan sifat yang ada pada manusia, dan mengenali karakteristik anggota keluarga untuk menemukan hukum pewarisan sifat) sebagai representasi basis saintifik, keduanya semula selalu diajarkan secara terpisah. Namun dengan pelatihan integrated learning model, keduanya dapat diintegrasikan dalam bentuk kegiatan yang saling mengkait. Hal ini dicontohkan pada seorang anak dari keturunan kyai tidak otomatis menjadi kyai jika tanpa upaya ikhtiar untuk menempa ilmu dengan sungguh-sungguh. Begitu juga sebaliknya sifat-sifat syukur dan qona'ah harus dimiliki oleh seiap orang dalam kondisi apapun, baik susah maupun senang. Dengan demikian dapat disimpulkan bahwa konsep yang mengandung nilai saintifik dan konsep yang mengandung nilai religious bukan hal yang dianggap terpisah, apalagi dikonflikkan/dilawankan. Keduanya dapat diintegrasikan dalam satu aktivitas pembelajaran dengan menggunakan integrated learning dengan connected model sampai immersed model.

\section{KESIMPULAN \& SARAN}

Berdasarkan hasil dan pembahasan kegiatan dapat disimpulkan bahwa pembelajaran dengan pendekatan integrated learning yang berbasis saintifik-religius bagi guru-guru di dua MTs swasta di kota Malang yang menjadi mitra kegiatan adalah materi pedagogis yang dianggap baru. Melalui kegiatan pengabdian ini mereka dapat berlatih tentang integrated learning yang memadukan matapelajaran Akidah Akhlak (matapelajaran agama) dan matapelajaran IPA/Biologi (matapelajaran umum). Melalui tema "perilaku terpuji keluarga sahabat nabi" dapat digunakan untuk mencapai kompetensi terkait dengan (1) ketepatan konsep pewarisan genetika, (2) urutan procedural tindakan, (3) kecepatan dalam mengenali sifat dan perilaku.

Saran dari kegiatan pengabdian ini adalah perlu peran serta aktif antara kepala sekolah dan guru dalam memahami konteks integrated learning. Perlu adanya pembinaan yang dilakukan oleh kepala sekolah dalam memahami konteks integrated learning pembelajaran berbasis saintifik dengan nilainilai religius.

\section{DAFTAR PUSTAKA}

Adnan, Amran, A, Asmah, S. (2020). Pengaruh Model Pembelajaran Meaningful Intructional Design ( MID ) terhadap Hasil Belajar Mata Kuliah Konsep Dasar IPA 2 Mahasiswa PGSD FIP UNM Makassar. Jurnal Publikasi Pendidikan Universitas Negeri Makassar, 10.

Akbar, S., Enrika, K., Hafi, D. Dwiharini, D. (2015). Pembelajaran Tematik: Konsep Dasar, Perancangan Perangkat, dan Implementasinya. UM Press.

Akbar, S. (2018). Pembelajaran Tematik. Malang. UM Press.

Anderson, J. R., Bothell, D., Byrne, M. D., Douglass, S., Lebiere, C., \& Qin, Y. (2004). An integrated theory of the mind. In Psychological Review. https://doi.org/10.1037/0033295X.111.4.1036

Birenbaum, M., Breuer, K., Cascallar, E., Dochy, F., Dori, Y., Ridgway, J., Wiesemes, R., \& Nickmans, G. (2006). A learning Integrated Assessment System. In Educational Research Review. https://doi.org/10.1016/j.edurev.2006.01. 001

Drianah, D. (2017). Strategi Pembelajaran Pendidikan Agama Islam dan Budi Pekerti melalui Joyfull and Meaningful Learning di Sekolah Dasar. Jurnal Kependidikan. https://doi.org/10.24090/jk.v5i2.2087

Fogarty, R. (1993). The Mindfull School: How to Integrate the Cuccicula. Hawker Brownlow: Skylight Publishing, Inc.

Hendriana, H., \& Afrilianto, M. (2017). Langkah Praktis Penelitian Tindakan Kelas Bagi Guru. Bandung: Refika Aditama.

Kim, D. (2015). A Study on the Class of Education that Builds Students' Character Through Films - Classes at the University of Liberal Arts. Procedia Social and Behavioral Sciences, 174, 1529-1533.

https://doi.org/10.1016/j.sbspro.2015.01. 784

Kovalik, S., \& Olsen, K. (1994). ITI: The model. integrated thematic instruction. Books for Educators, Covington Square. Covington Square, 17051 SE 272nd Street, Suite 18, Kent, WA 98042.

Miaz, Y., \& Putra, R. P. (2020). Pelatihan Penulisan Penelitian Tindakan Kelas Untuk Guru Sekolah Dasar. Jurnal Nurul Ulfatin ${ }^{1}$, Maisyaroh $^{2}$, Djum-Djum Noor Benty ${ }^{3}$, Bagus Rachmad Saputra ${ }^{4}$, Amat Mukhadis $^{5}$. Implementasi Integrated Learning Berbasis Saintifik... , halaman 146-153 
Publikasi Pendidikan Universitas Negeri Makassar, 10.

Riyanta, T. (2016). MENGEMBANGKAN BUDAYA MUTU SEKOLAH MELALUI KEPEMIMPINAN TRANSFORMASIONAL. Jurnal Manajemen Pendidikan UNY.

Trianto. (2007). Model Pembelajaran Terpadu: Teori dan Praktik. Prestasi Pustaka Publisher.

Ulfatin, N dan Mukhadis, A. (2018). Pengembangan Kurikulum Belajar dan Berkarya. Malang. UM Press.

Ulia, N., \& Hariyono, M. (2020). Pendampingan Kelompok Siswa Remedial Melalui Klinik Cerdas Diagnostik Berbasis Collaborative Learning. Jurnal Publikasi Pendidikan Universitas Negeri Makassar, 10, 37-44. 